TITLE:

\title{
Characteristics of meltwater and/or rainfall regime in a snowy region and its effect on sediment-related disasters
}

\section{$\operatorname{AUTHOR}(S):$}

Matsuura, Sumio; Okamoto, Takashi; Asano, Shiho; Matsuyama, Koji

\section{CITATION:}

Matsuura, Sumio ...[et al]. Characteristics of meltwater and/or rainfall regime in a snowy region and its effect on sediment-related disasters. Bulletin of Engineering Geology and the Environment 2013, 72(1): 119-129

\section{ISSUE DATE:}

2013-02

URL:

http://hdl.handle.net/2433/173182

\section{RIGHT:}

The final publication is available at www.springerlink.com; この論文は 出版社版でありません。引用の際には出版社版をご確認ご利用くださ $\omega_{\circ}$; This is not the published version. Please cite only the published version. 


\title{
Characteristics of meltwater and/or rainfall regime in a snowy region and its effect on sediment-related disasters
}

\author{
Sumio MATSUURA ${ }^{1}$, Takashi OKAMOTO ${ }^{2}$, Shiho ASANO $^{2}$ and Koji \\ MATSUYAMA ${ }^{3}$ \\ ${ }^{1}$ Kyoto University, Gokasyo, Uji, Kyoto, 611-0011, Japan \\ +81-774-38-4116, +81-774-38-4118, matsu03@ @scs.dpri.kyoto-u.ac.jp \\ ${ }^{2}$ Forestry and Forest Products Research Institute, P.O. Box 16, Ibaraki 305-8687, \\ Japan \\ ${ }^{3}$ Forestry Agency, 1-2-1, Kasumigaseki, Chiyoda, Tokyo 100-8950, Japan
}

\begin{abstract}
Meltwater and/or rainfall (MR) were monitored using lysimeters for eleven years in a mountainous region in the north-central part of Japan, where a seasonal snowpack forms, to collect basic data sets for understanding MR regime and sediment-related disasters. Statistical analyses of the data showed that high hourly MR intensities were mainly observed as rain during the non-snow cover period, but the annual maximum daily MR appeared often during the snow cover period. The longer the time unit, the greater the shift in maximum MR values from the non-snow to snow cover periods. For a time unit of 70 hours, almost all maximum values were recorded during snowmelting periods. MR regime, that is to say, timing, intensity and duration of MR regulate the characteristics of sediment-related disasters such as debris flows, slope failures and landslides. In the case of deep-seated landslides, if there are no accurate observations of MR during the snow cover period, the degree of risk may be underestimated. Furthermore, when designing groundwater discharge works to prevent deep-seated landslides, the timing, intensity and duration of MR must be accurately evaluated to effectively discharge groundwater during the snowmelting period.
\end{abstract}

KEY WORDS: meltwater and/or rainfall (MR), MR regime, lysimeter, snowy region, sediment-related disasters

\section{Introduction}

In snowy regions, rain reaches the ground surface directly, but snow is stored in the snowpack and is discharged to the ground surface later at various times and intensities. Thus, the regime of water reaching the ground surface 
during the snow cover period are not thoroughly understood, making it difficult to evaluate the risk of sediment-related disasters.

Monitoring of the water reaching the ground surface in snowy regions has been conducted using lysimeters to investigate the runoff of chemical components in the snow (Berris and Harr, 1987), the effects of changes in forest conditions on microclimates in forest zones (Harrington and Bales, 1998), the process of snowmelt (Williams et al., 1999; Erickson and Williams, 2003; Tekel1 et al., 2005), and the formation of preferential flow paths within snowpacks (French and van der Zee, 1999).

Monitoring using lysimeters has also been conducted to investigate landslides triggered by snowmelt (Ogawa et al., 1987), but only during the snow cover period, and few investigations have been carried out on fluctuations in water reaching the ground surface. To understand the mechanisms of sedimentrelated disasters in snowy regions, the behavior of water reaching the ground surface beneath the snowpack must be investigated at intervals of no longer than one hour.

Therefore, we constructed a monitoring station (Busuno Station) in a snowy mountainous region and have monitored the water reaching the ground surface and seasonal snowpack conditions since December 1987. This paper describes the statistical characteristics of the timing, intensity and duration of water reaching the ground surface based on the monitoring data recorded between 1988 and 1999. These characteristics are indispensable for understanding the mechanisms of sediment-related disasters, evaluating the risk of disasters, formulating warning and evacuation indices, and planning and constructing disaster prevention works.

\section{Methods}

\section{Overview of the monitored region}

Mountains that are several hundred meters in elevation and composed of semi-consolidated Tertiary soft rocks lie along the Sea of Japan in the central to northern part of Japan. The area is covered by 3 to $5 \mathrm{~m}$ of snow in winter, and sediment-related disasters, such as slope failures and landslides, occur frequently. 
A monitoring station was established on a gentle slope $567 \mathrm{~m}$ in elevation. The station is vegetated with Cryptomeria japonica and Quercus crispula (Figure 1).

The mean annual precipitation in this region is almost $3,000 \mathrm{~mm}$, which is about 1.8 times greater than the mean annual precipitation in Japan $(1,690 \mathrm{~mm})$. Snow accounts for 40 to $50 \%$ of the precipitation, and the rest is rain, which falls mainly during the rainy season of June and July, during the typhoon season of September and October, and, unlike the other regions of Japan, in November and early December as well.

The first snow usually occurs in November, and by early December, a continuous snowpack is formed over the ground surface and lasts for about 5 months until early May. The mean maximum snow depth is about $360 \mathrm{~cm}$, but $464 \mathrm{~cm}$ was recorded in February 1996. During such a heavy snow season, approximately $1,600 \mathrm{~mm}$ of water, which is equivalent to the mean annual precipitation in Japan, is stored on the ground surface in the form of snowpack (Matsuura et al., 2005).

In this paper, the term snowmelting period denotes the period from the day when the maximum snow water equivalent is recorded to the day when the snowpack disappears. Therefore, the dates when the snowmelting period begins vary by year.

\section{Monitoring methods}

Lysimeters are the most appropriate tools for monitoring the water reaching the ground surface. In the present study, four stainless steel lysimeters $(1.0 \mathrm{~m} \times 1.0 \mathrm{~m} \times 0.2 \mathrm{~m})$ were buried in the ground, leaving about $3 \mathrm{~cm}$ exposed above the ground, and were filled with coarse silica sand. Water captured by the lysimeters at the ground surface was transmitted to a 500cc tipping bucket discharge gauge, and the amount of water was determined by counting the pulses (Figure 2).

In this paper, the water monitored by the lysimeters is referred to as "meltwater and/or rainfall" (MR). Water captured by the lysimeters is rainwater when there is no snow cover, and meltwater when there is snow cover. When it rains on the snowpack, water that reaches the ground surface never consists of rainwater alone but is always a mixture of rainwater and meltwater. 
The snowpack is melted by mainly shortwave radiation, latent heat fluxes, sensible heat fluxes and rainwater. The rainwater which infiltrates the snowpack immediately mixes with meltwater. Although some of the rainwater is stored temporarily, it is ultimately discharged to the ground from the bottom of the snowpack. Thus, the lysimeters capture "rainfall", "meltwater", and "meltwater + rainfall”.

Meltwater and/or rainfall (MR) can also be estimated by monitoring the snow water equivalent. Thus, snow water equivalent was monitored using a metal-wafer-type gauge consisting of a pressure sensing plate filled with an antifreeze solution and a semiconductor pressure sensor (Greydamus, 1976). The measurement accuracy was $0.125 \mathrm{~mm}$ for the lysimeters and $2 \mathrm{~mm}$ for the metalwater-type gauge. We have also monitored snow depth using ultrasonic gauges and other related meteorological factors at one-hour intervals since December 1987 and at 30-minute intervals since August 1991.

\section{Methods for interpolating data sets}

A MR data set of 1-hour intervals for the entire monitoring period was prepared by interpolating missing or unreliable MR data using simple tank models. However, the processing methods differed between snow and non-snow cover periods (Figure 3 ).

The daily data from the lysimeters and rain/snow gauges were closely correlated during the period with no snowpack. However, a time lag of 0-3 hours was observed among the hourly data depending on previous rainfall since the lysimeters were filled with silica sand. Thus, a tank model was prepared to calculate MR from rainfall data. The tank model of the lysimeter has a very simple structure with an outlet on one side. Parameters such as height of runoff hole $\left(h_{1}\right)$ and evaporation rate $\left(e_{1}\right)$ were determined using data obtained when rainfall was observed after a long period of dry weather. The coefficient of runoff hole $\left(\mathrm{k}_{1}\right)$ was determined by the characteristics of discharge corresponding to the rainfall.

MR of the non-snow cover period was calculated by inputting rainfall data to the tank model, and the monitored and calculated values were closely correlated (Figure 4). Thus, the model was used to interpolate hourly missing data of MR caused by malfunctioning sensors and system failure in the non-snow 
cover period. When the rainfall data were also missing, they were estimated from the correlation of hourly rainfall data between Busuno Station and Yasuzuka Station approximately $6.7 \mathrm{~km}$ to the north.

Meltwater and rainwater do not usually infiltrate vertically but rather flow through preferential paths in the snowpack (Colbeck, 1978; Marsh and Woo, 1984; Kattelmann, 1989). Although the lysimeters used at Busuno Station have a water collection area of $4 \mathrm{~m}^{2}$, they have frequently been unable to measure the correct amount of water especially during snowmelting periods due to preferential flow paths that developed within the snowpack.

Rainwater that falls on snowpack and snow that melts at the surface show time lags and changes in intensity and duration until they are discharged to the ground surface (Kojima and Motoyama, 1984; Singh et al., 1997). To reproduce these phenomena, tank models have been proposed (Motoyama, 1986; Hayakawa, 1994).

In the present study, a tank model of the snowpack was prepared to accurately estimate the MR supplied to the ground through the snowpack on the lysimeters during a snowmelting period. The model was equipped with a runoff hole, and the coefficient of the runoff hole $\left(\mathrm{k}_{0}\right)$ was exponentially proportional to snow depth. The initial height of the runoff hole was assumed to be $0 \mathrm{~mm}$ since the maximum snow water equivalent was recorded and the snowpack should not have any water storage capacity. This is why we set a runoff hole not on the side but at the bottom of the tank. According to Bengtsson (1980) and Kojima (1986), the evaporation rate in cold regions varies from 0.3 to $0.6 \mathrm{mmd}^{-1}$. We set the evaporation rate as $1 \mathrm{mmd}^{-1}$ because of the low latitude of the research site. We think that the used value does not greatly affect the results since the rate of evaporation is much smaller than the rate of melting in the snowmelting period.

MR values during snowmelting periods were calculated by combining the models of the snowpack and inputting the difference in snow water equivalent and rainfall. The resultant calculated values and monitored values had a slightly lower correlation than those for the non-snow cover period (Figure 4), but the calculation satisfactorily reproduced the intensity and timing of hourly MR during the snowmelting period. Thus, the MR data for eleven snowmelting periods (the period from the recorded day of maximum snow water equivalent to the day of disappearance of snow) were replaced with calculated values. 
A small amount of MR data was missing from the days on which snow started to accumulate to the days on which the maximum snow water equivalent was recorded. Moreover, almost all MR values during the periods were meltwater from the bottom of the snowpack of about 0.6 to $1.5 \mathrm{mmd}^{-1}$ caused by ground heat fluxes. Thus, the missing values were interpolated with values monitored on nearby days. Meltwater was recorded even during the coldest months of January and February for all the monitoring years, suggesting that there was no ground frost.

\section{Results and discussion}

\section{Setting water years}

Appropriate water years for MR should be determined to statistically analyze the data. Setting changes of water years in months when MR shows large changes may result in large MR events occurring in a water year or in the following water year, depending on slight fluctuations in meteorological conditions in the year, and thus large fluctuations in statistics from one year to another.

Therefore, using the MR data from May 1, 1988 to June 30, 1999, mean annual MR values were calculated using each month as the starting month of a year (from the first day of each month to the last day of the previous month in the next year). For each starting month, the standard deviations of eleven annual MR values were calculated, and the month with the smallest standard deviation was defined as the starting month of a water year. The precipitation data at Busuno and Yasuzuka Stations were also similarly processed.

The data processing showed that the standard deviation of MR was smallest for water years starting in June (Figure 5). On the other hand, the precipitation data from Busuno Station showed the smallest standard deviation for years starting in July but there was no great difference from June. In this study, we decided to use water years starting on June 1 and ending on May 31 of the next year. For example, water year 91/92 (hereafter referred to as "91/92”) denotes the period starting on June 1, 1991 and ending on May 31, 1992. 
In this region, continuous seasonal snowpack starts in early December and disappears in late April to early May in ordinary years, and the rainy season (baiu) starts in mid to late June. Thus, changes in MR should be least in May and June. Actually, the average minimum daily MR in the eleven water years was recorded on June 8 , and the moving average for 3 to 7 days also showed minimum daily MR values in late May to early June.

\section{MR during the eleven water years}

At Busuno Station, annual precipitation in the eleven water years ranged from 2,690 to $3,240 \mathrm{~mm}$, half of which was likely to be snow. The amount of snowfall differed greatly between years, and thus the resultant temporary seasonal snowpack conditions. In winters of heavy snowfall, over 1,600 $\mathrm{mm}$ of water was stored in the form of snowpack, which melted at various times and intensities during the snowmelting periods and was discharged to the ground surface.

MR values were almost proportional to precipitation and were 2,480 to $3,440 \mathrm{~mm}$ in the eleven water years, which varied slightly more than precipitation. This was attributable to differences between precipitation and MR during the snow cover periods, which were caused mainly by wind-induced erosion and accumulation of the snowpack.

The largest annual MR value was recorded in 95/96, and the smallest in $88 / 89$. In $95 / 96$, especially large MR values were recorded in the early snow cover period and during the snowmelting period, at the end of which large amounts of MR were discharged to the ground surface almost every day. During the mid snow cover periods in January and February, MR was only 0.6 to $1.5 \mathrm{mmd}^{-1}$, and was most likely water that had melted from the bottom of the snowpack. On the other hand, in 88/89, when there was little snow and a thin snowpack, MR was observed throughout nearly the entire snow cover period. Even in the coldest months of January and February, 60 to $70 \mathrm{mmd}^{-1}$ of MR was recorded (Figure 6).

\section{Hourly MR intensities and days of large hourly MR values}

In all water years except 97/98, the maximum hourly MR value was recorded in the non-snow cover period, mostly in August followed by July and 
September, during severe local rains caused by stationary fronts, storms caused by cold fronts, and typhoons (Table 1). The maximum monitored value of all water years was $39.7 \mathrm{mmh}^{-1}$ on July 11, 1995 (95/96). For several days including this one, the region along the Sea of Japan in the Chubu area was hit by heavy storms caused by a baiu front and suffered serious damage from debris flows and landslides. A number of shallow landslides also occurred near Busuno Station.

The maximum hourly MR values during the snow cover period ranged from 10 to $14 \mathrm{~mm}$ and were more stable than those occurring during the non-snow cover period. Therefore, MR values during the snow cover period were relatively small when there were intensive rainfall events in the non-snow cover period of the same water year and were relatively large when there were no such events. The stable MR intensities are probably attributable to the buffer effect of snowpack.

The top 50 hourly MR values in these eleven water years were extracted (Figure 7), the majority of which occurred in the non-snow cover period and only five were recorded in the snow cover period. This shows that intensive hourly MR usually occurred during rains in the non-snow cover period.

\section{Daily MR intensities and days of large daily MR values}

Similar to hourly MR intensities, the five largest daily MR values of each water year were analyzed. Daily MR denotes the total MR from 0 to 24 hours. The analysis showed that, unlike hourly MR, large daily MR values were observed in the snow cover period of all the water years except 95/96 and 98/99 (Table 2). The maximum daily MR values ranged from 90 to $180 \mathrm{~mm}$, the largest of which was recorded on April 12, 1994 (93/94). The second largest was on March 4, 1989 (88/89), when the foehn phenomenon occurred and the meltwater mixed with rainwater.

Of the nine maximum values recorded in the snow cover period, seven were in snowmelting periods. In 91/92 and 96/97, MR values of approximately $100 \mathrm{~mm}$ were recorded in the early snow cover periods during rains caused by low-pressure cyclones. Rains on snowpack cause large amounts of MR to be discharged to the ground surface (Harr, 1981). The rain itself may not have melted much snow, but it was accompanied by humid winds, the latent heat flux of which melted large volumes of snow. 
Unlike hourly MR, most of the top 50 daily MR values in the eleven winter years were concentrated in the snow cover period, especially in the snowmelting period (Figure 8), including three that were recorded in the early snow cover period. The MR intensity distribution shifted from non-snow to snow cover period when longer time units were used.

\section{Relationship between MR time unit and intensity}

The maximum hourly and daily values appeared in completely different seasons. To understand the relationship between time unit and MR intensity, we determined the maximum values for time units of 1 to 72 hours and the seasons when the values were recorded for each water year (Table 3). The maximum MR value for a specific time unit was defined as the largest MR value for a continuous period of said time unit. Therefore, the maximum 24-hour MR value may differ from the maximum daily MR.

The results differed completely between 95/96 and 97/98. In 97/98, when it did not rain continuously or intensively for a short duration, all of the maximum 1- to 72-hour MR values were recorded in the snow cover period. On the other hand, in 1996, when the largest hourly precipitation of the eleven water years was recorded and local and heavy rains fell for four days due to a stationary front, all the maximum 1- to 36-hour MR values were recorded during this period.

As described in the previous section, when we examined the longer time unit, we found that the greater maximum MR values were recorded during the snow cover period. The percentage of maximum MR values recorded in the snow cover period was approximately $10 \%$ for a time unit of one hour and about $60 \%$ for 10 hours, and almost all of the 70-hour maximum values were recorded in the snow cover period (Figure 9).

\section{Effect of MR characteristics on sediment-related disasters}

The characteristics of MR regime, namely timing, intensity and duration of MR, seem to have a large effect on the types of sediment-related disasters which occur not only in this district but also other snowy regions. Thus, based on the 
MR data of 88/89 and 95/96, the relationship between MR and sediment-related disasters was studied using a standard index used in Japan.

There have been various researches on scientific and rational warning and evacuation indices for mitigating sediment-related disasters during heavy rainfall in Japan. Senoo and Funazaki (1973) showed that the slope instability is governed by both cumulative rainfall and intensity of rainfall. A method using effective rainfall instead of cumulative rainfall has been developed (Senoo et al., 1985; Yano, 1990), and the Ministry of Construction customized it using long-term and short-term effective rainfall in 1993.

In this method, first, the rains during which sediment-related disasters occurred and the rains during which they did not occur are extracted from the rainfall records. The critical line (CL) is estimated from the scattered data in the figure with long-term effective rainfall before the disaster plotted on the $\mathrm{X}$-axis and short-term effective rainfall just before the disaster plotted on the Y-axis. When the snake line (SL), which is plotted on these coordinates provided every hour by a meteorological station, approaches CL, it means that the risk of sediment-related disasters rises.

The effective rain of a 72-hour half-life time on the $\mathrm{X}$-axis and effective rain of 1.5 hours on the $\mathrm{Y}$-axis are used as the standard rains in this study. The effective rain is then calculated as follows (Yano, 1990):

$$
E M R=\sum \alpha_{1 \mathrm{i}} \times M R_{1 \mathrm{i}}
$$

Where EMR: effective MR; $\mathrm{MR}_{1 \mathrm{i}}$ : the 1-hour MR i hours beforehand; and $\alpha_{1 \mathrm{i}}$ : the reduction coefficient $i$ hours beforehand. In addition, $\mathrm{T}$ is the half-life (time) at $\alpha_{1 \mathrm{i}}$ $=0.5^{\mathrm{i} / \mathrm{T}}$.

This method, in which MR is substituted for rainfall, was used to create the snake line of the non-snow cover period of 95/96 (SLns) and the snake curve of the snow cover period (SLsc) in Figure 10. Since continuous MR was observed during the snow cover period, the 72-hour effective MR became high values with a cyclic path. However, the 1.5-hour effective MR was not large due to the calm snowmelting period with a relatively low intensity of MR (10-13 $\left.\mathrm{mmh}^{-1}\right)$. In contrast, large amounts of high-intensity rain fell in July 1995, so the 1.5-hour effective MR was very large. In the area around Busuno Station, there have been many occurrences of shallow landslides, so the snake curve is estimated to have reached CL. 
On the other hand, $19.5 \mathrm{mmh}^{-1}$ of $88 / 89$ 's maximum hourly MR was caused by rainfall while the foehn of March 4 and subsequent rains resulted in a high-intensity MR (164.2 $\left.\mathrm{mmd}^{-1}\right)$ during the light snow cover period. Although the maximum hourly MR of $13.4 \mathrm{mmh}^{-1}$ was not particularly intensive, the 72hour effective MR became high due to the continuous supply of MR during this event. This caused a deep-seated landslide $6 \mathrm{~km}$ north of Busuno Station (Figure $11)$.

Sediment-related disasters, such as debris flows, slope failures and landslides, are closely related to rainfall regimes. Debris flows, slope failures and shallow landslides are caused by short duration, intensive rainfall, and deep-seated landslides are caused by prolonged, heavy rainfall (Fukuoka, 1980; Caine, 1980; Gerald and Olivier, 1993; Corominas and Moya, 1999; Cai and Ugai, 2004; Saito, Nakayama and Matsuyama 2010). This is because even if the intensity is low, if it is continuous, the water that reaches the surface will often infiltrate deep underground and increase the pore-water pressure. Although the degree of landslide risk depends on geo-hydrological conditions, geomorphological features and geological structures, deep-seated landslides are caused by the lowering of the effective stress with high pore-water pressure (Skempton, 1964; Ogawa et al., 1987).

In the study area, deep-seated landslides tend to occur during the smowmelting period as in the case of $88 / 89$. On the other hand, slope failures and shallow landslides have been caused by intensive rainfall. Thus, it became quantitatively clear that the timing, intensity and duration of MR regulate the characteristics of sediment-related disasters.

\section{Effects of considering snow cover period on extreme value distribution}

The extreme value distributions of hourly and daily data for the non-snow cover period (MRns) of the eleven water years were compared with those for the non-snow and snow cover periods combined (MRis) using the Gumbel-Chow method (Chow, 1964). Of the eleven water years, only one year showed a maximum hourly MR in the snow cover period, with a small value of only 13 $\mathrm{mmh}^{-1}$. Therefore, for hourly MR, the extreme value distribution was hardly affected by the data collected during the snow cover period (Figure 12). 
On the other hand, for daily MR, data collected in the snow cover period produced large differences. For example, the return period for $153 \mathrm{mmd}^{-1}$ of water to reach the ground surface was five years when calculated using the data from the snow cover period, and about 22 years without using these data (Figure 13). The calculated return periods show that extreme events in heavy-snow areas occur quite frequently.

A sensitivity analysis was conducted to understand the effects of considering data in the snow cover period on MR of certain return periods (Figure 14). The $\mathrm{X}$-axis of the figure shows the return period, and the $\mathrm{Y}$-axis shows MR values for only the non-snow cover period (MRns) divided by MR values for both the non-snow and snow cover periods (MRis). For hourly MR, the ratios varied little by return period.

Daily MR values, however, showed a sharp drop in MRns/MRis when shorter return periods were used. For example, MR that occurred with a return period of 50 years was calculated to be $174 \mathrm{~mm}$ when the data for snow cover period were not used, and $217 \mathrm{~mm}$ when the data were used. MR values of a return period of 1.6 years were $64 \mathrm{~mm}$ and $114 \mathrm{~mm}$, respectively (Figure 13).

Therefore, events that occur within a short time unit, such as hourly MR, can be analyzed using only the data for the non-snow cover period. However, events that occur within a long time unit, such as daily MR, should be analyzed using the data for the snow cover period.

In addition, civil engineering works to prevent or mitigate sediment-related disasters like debris flow in snowy areas are generally designed taking hourly precipitation into consideration, and few problems arise. However, when we design deep wells and drainage tunnels for draining groundwater to prevent deepseated landslides, the intensity and duration of MR during snow cover periods should be correctly evaluated since a large quantity of MR supplied over a long period can lead to excess groundwater with high pore-pressure forming during the snowmelting period.

\section{Conclusions}

Meltwater and/or rainfall (MR) were monitored using lysimeters for eleven years in a mountainous district where seasonal snowpack is formed, in order to collect 
basic data sets for understanding the mechanisms of sediment-related disasters, evaluating the risks of disaster and planning effective disaster prevention works.

An investigation of the MR regime based on water years showed that high hourly MR intensities were mainly observed as rain during the non-snow cover period, and the annual maximum daily MR appeared most often during the snow cover period. The longer the time unit, the greater the shift in maximum MR values from non-snow to snow cover period. For a time unit of 70 hours, almost all maximum values were recorded during snowmelting periods. This was because the water stored in snowpack was melted by the seasonal increase in air temperature and solar radiation, resulting in water discharging to the ground almost every day.

Thus, in regions where a seasonal snowpack is formed and the geology and geomorphology are highly unstable, the timing, intensity and duration of MR control the characteristics of sediment-related disasters, especially during the snow cover period. That is to say, slope failures and shallow landslides are caused by intensive rainfall in the non-snow cover period while deep-seated landslides tend to be induced by a continuous supply of MR originating from meltwater and rain on snowpack during the snow cover period.

Generally, few problems arise when we predict the degree of risk of shallow landslides or debris flow since it is easy to observe rainfall. However, it is difficult to observe precisely how much water flows from the bottom of the snowpack to the ground surface in the snow cover period. Therefore, we are apt to underestimate the risk of deep-seated landslides which tend to occur during the snow cover period, especially in the snowmelting period.

The design of deep-seated landslide prevention works like drainage wells and deep wells requires appropriate data and dimensions to reduce the excess pore-water pressure effectively. If there is no accurate evaluation of MR during the snow cover period, the drainage well may be submerged due to excessive groundwater and in the worst case it can lead to the re-activation of the landslide. Thus, it is evident that there must be an accurate evaluation of the timing, intensity and duration of MR in a snowy region. 


\section{References}

Bengtsson, L. (1980): Evaporation from a Snow Cover -Review and Discussion of Measurements, Nordic Hydrology, 11, 221-234

Berris, S. N. and Harr, R. D. (1987): Comparative snow accumulation and melt during rainfall in forested and clear-cut plots in the western Cascades of Oregon. Water Resources Research, 23(1), 135-142.

Cai, F. and Ugai, K. (2004): Numerical analysis of rainfall effects on slope stability, International Journal of Geomechanics, 4, 69-78.

Caine, N. (1980): The rainfall intensity-duration control of shallow landslide and debris flows. Geografiska Annaler, 62A, 23-27.

Chow, V. T. (1964): Handbook of Applied Hydrology, McGraw-Hill, New York, 8-25.

Colbeck, S. C. (1978): The physical aspects of water flow through snow, Adv. Hydrosci., 11, 165206.

Corominas, J. and Moya, J. (1999): Reconstructing recent landslide activity in relation to rainfall in the Llobregat River basin, Eastern Pyrenees, Spain, Geomorphology, 30(1-2), 79-93.

Erickson, T. A. and Williams, M. W. (2003): The Soddie Lysimeter Array: Spatially-variable Snowmelt Data and Analyses, International Workshop on Mountain Hydrology, Switzerland, 24.

French, H. K. and van der Zee, S. E. A. T. M. (1999): Field observations of small scale spatial variability of snowmelt drainage and infiltration, Nordic Hydrology, 30, 161-176.

Fukuoka, M. (1980): Landslides associated with rainfall, Geotechnical Engineering, 11, 1-29. Gerald, G. and Olivier, J. (1993): Predicting landslides from rainfall in a humid, sub-tropical region. Geomorphology, 8, 165-173.

Greydanus, H. W. (1976): Snow Sensor Evaluation in the Sierra Nevada California Cooperative Snow Surveys, State of California Resources Agency, Department of Water Resources, Division of Planning, 1-155.

Harr, R. D. (1981): Some characteristics and consequences of snowmelt during rainfall in Western Oregon, Journal of Hydrology, 53, 277-304.

Harrington, R. and Bales, R. C. (1998): Interannual, seasonal, and spatial patterns of meltwater and solute fluxes in a seasonal snowpack, Water Resources Researches, 34(4), 823-831.

Hayakawa, K. (1994): Estimation of the Daily Snowmelt Water Runoff from the Bottom of Snow Cover, Journal of Japanese Association of Hydrological Sciences, 24(4), 207-219. (in Japanese with English abstract)

Kattelmann, R. C. (1989): Spatial variability of snow-pack outflow at a site in the Sierra Nevada, Annals of Glaciology, 13, 124-128.

Kojima, K. and Motoyama, H. (1984): Time lag of meltwater percolation through a snow cover. Low Temperature Science, Ser, A 43, 181-184. (in Japanese)

Kojima, K. and Takahashi, S. (1986): Observed Rate of Evaporation at the Surface of a Snow Cover-Additional Observations in January and February, 1985 in Sapporo and Kitami, Hokkaido, Low Temperature Science, Ser. A, 44, 31-38. (in Japanese) 
Marsh, P. and Woo, M. (1984): Wetting front advance and freezing of meltwater within a snow cover: 1. Observations in the Canadian Arctic, Water Resources and Research, 20(12), 1853-1864 Matsuura, S., Matsuyama, K., Okamoto, T., Asano, S. and Takeuchi, Y. (2005): Fluctuation of the seasonal snowpack in a mountainous area of the heavy snow district in the warm-temperate zone in Japan, Journal of Glaciology, 51, 547-554.

Motoyama, H. (1986): Studies of Basin Heat Balance and Snowmelt Runoff Models, Contribution of the Institute of Low Temperature Science, 2930, 1-53.

Ogawa, S., Ikeda, T., Kamei, T. and Wada, T. (1987): Field investigations on seasonal variations of the groundwater level and pore water pressure in landslide areas, Soil and Foundations, 27(1), $50-60$.

Saito, H., Nakayama, D. and Matsuyama, H. (2010): Relationship between the initiation of a shallow landslide and rainfall intensity - duration thresholds in Japan, Geomorphology, 118, 167175 .

Senoo, K. and Funazaki, M. (1973): The relationship between sediment-related disasters (mainly debris flow) and rainfall, J. of the Japan Society of Erosion Control Engineering, 26(2), 22-28. (in Japanese)

Senoo, K., Godai, H., Hara Y. and Shiojima, Y. (1985): Rainfall Indexes for Debris Flow Warning Evacuating Program, J. of the Japan Society of Erosion Control Engineering, 38(2), 16-21. (in Japanese with English abstract)

Singh, P., Spitzbart, G., Hubl, H. and Weinmeister, H. W. (1997): Hydrological response of snowpack under rain-on-snow events: a field study, Journal of Hydrology, 202(1-4), 1-20. Skempton, A.W., 1964. Long-term stability of clay slopes. Geotechniques 14 (2), 77-102. Tekelı, A. E., Şorman, A. A., Şensoy, A., Şorman, A. Ü., Bonta, J. and Schaefer, G. (2005): Snowmelt Lysimeters for Real-Time Snowmelt Studies in Turkey, Turkish Journal of Engineering and Environment Science, 29, 29-40.

Williams, M.W., Cline, D., Hartman, M. and Bardsley, T. (1999): Data for snowmelt model development, calibration, and verification at an alpine site, Colorado Front Range, Water Resources Research, 35-10, 3205-3209.

Yano, K. (1990): Study of the method for setting standard rainfall of debris flow by the reform of antecedent rain, Japan Society of Erosion Control Engineering, 43(4), 3-13. (in Japanese with English abstract) 


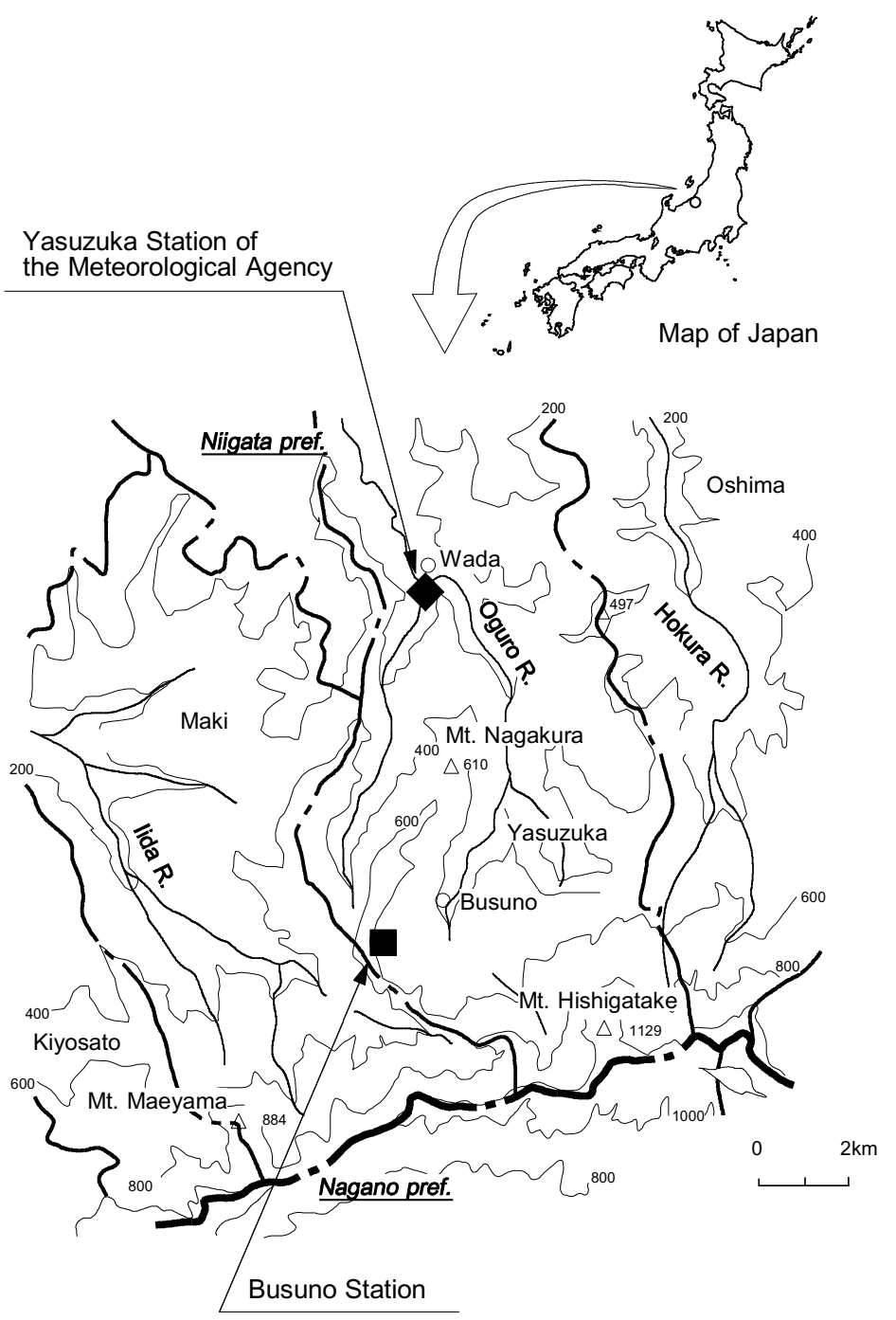

Figure 1 Location map of Busuno Station. 


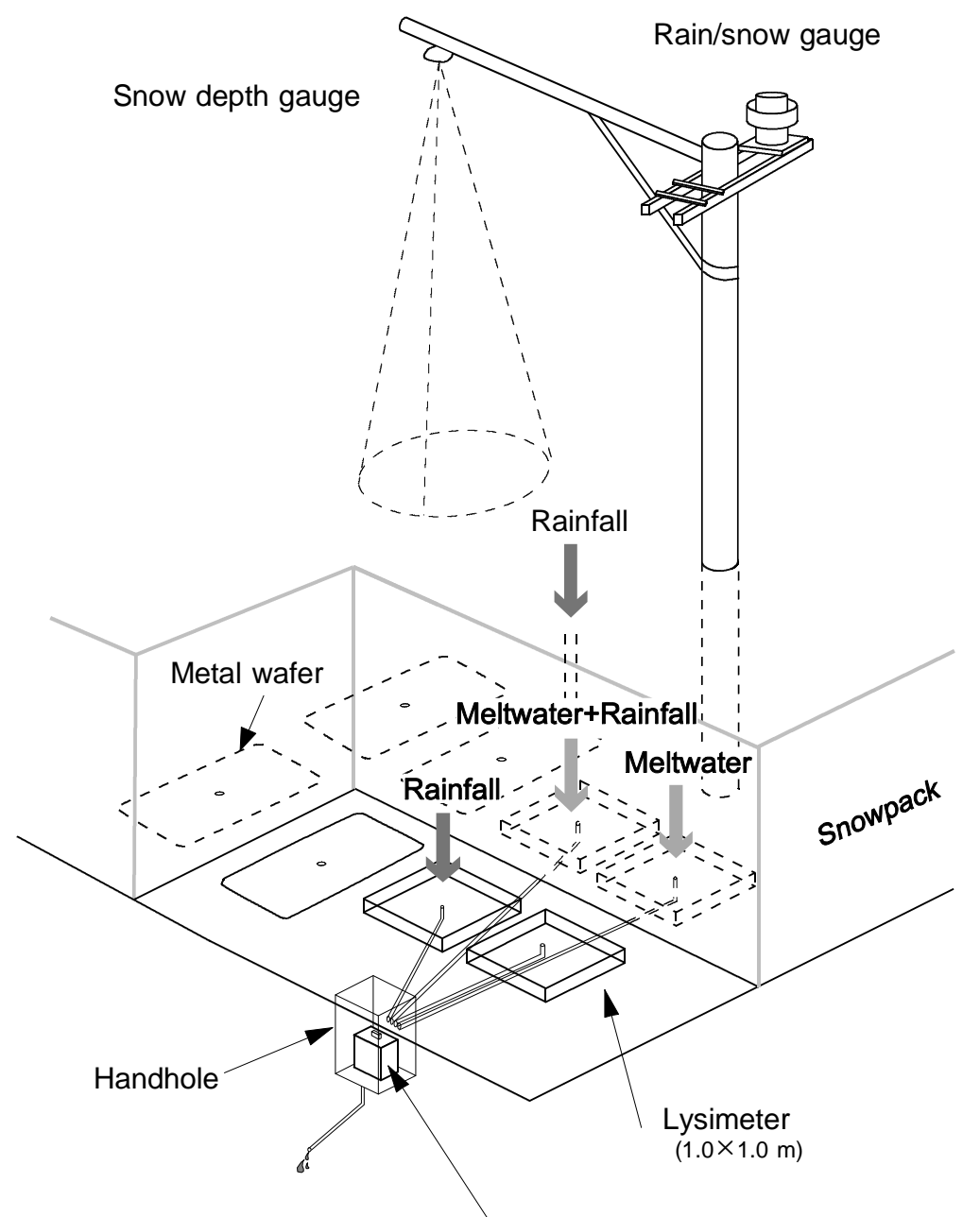

Tipping backet discharge gauge

(500cc)

Figure 2 Schedumatic diagrame of MR monitoring system. 


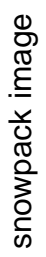
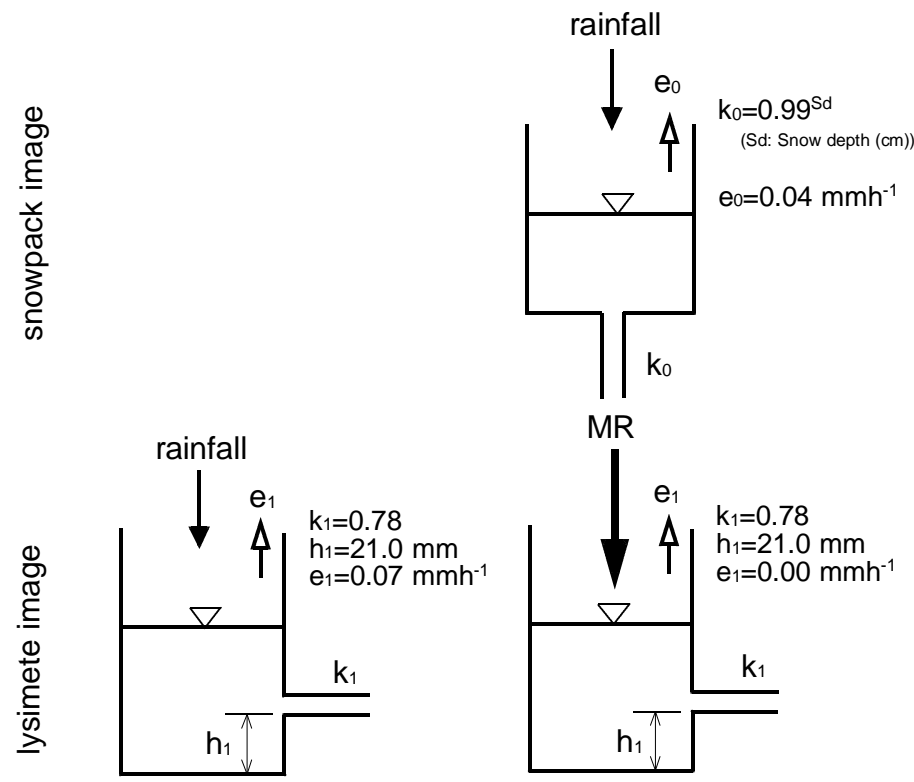

Non-snow cover season

Snow cover season

Figure 3 Structure of tank models for interpolating missing data in non-snow cover season and snow cover seasons. 

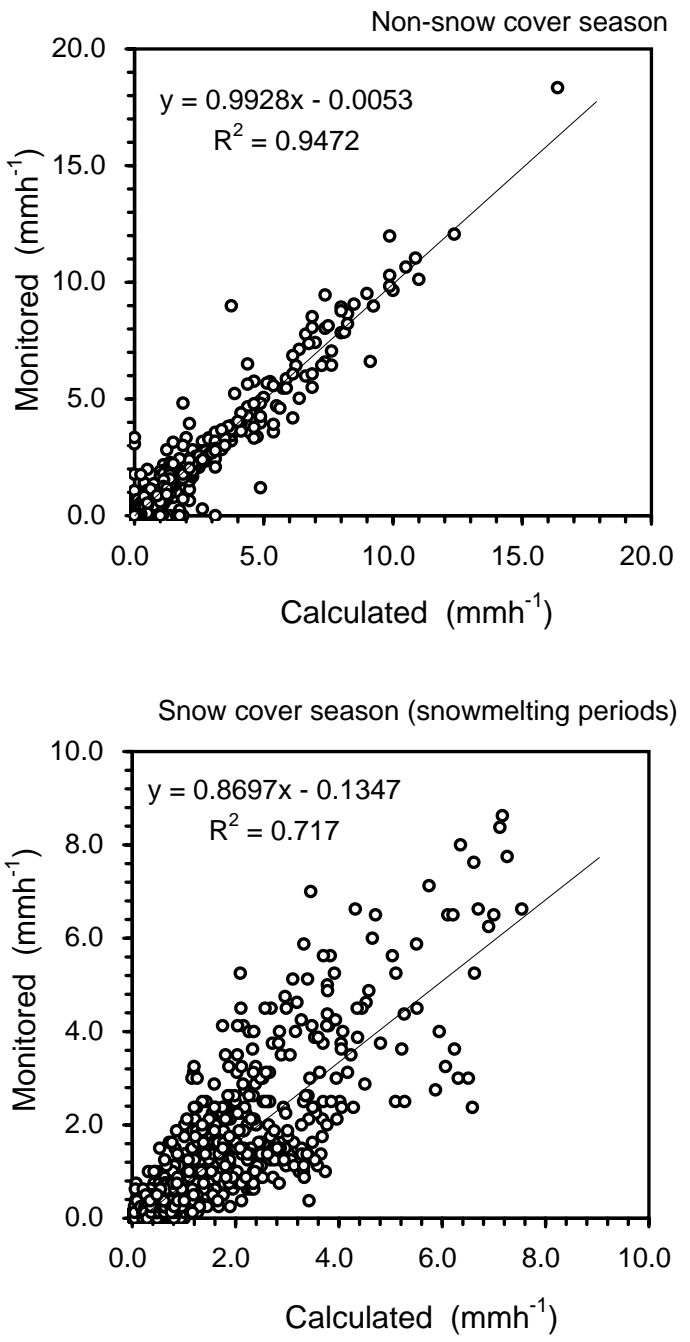

Figure 4 Relationship between the calculated values by the tank model and the monitored values bv the Ivsimeter. 


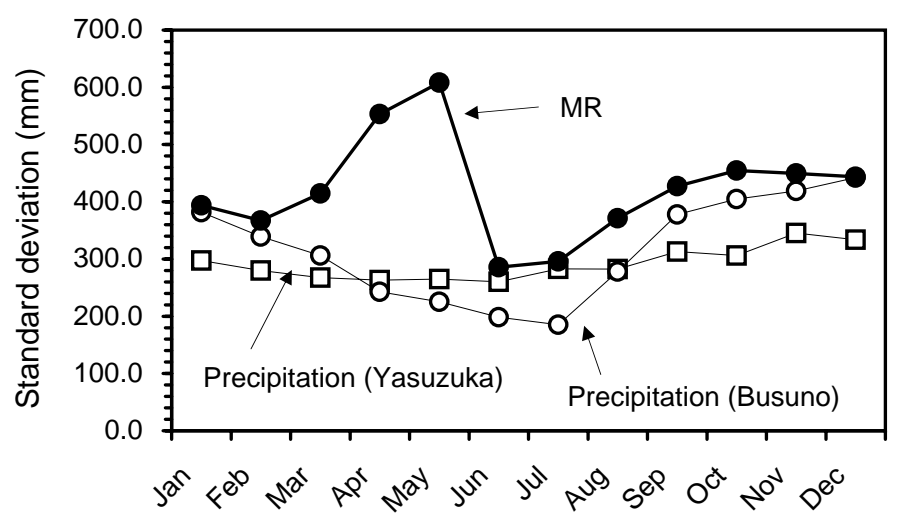

Figure 5 Variation of standard deviations in each month used as the start of the water year. 

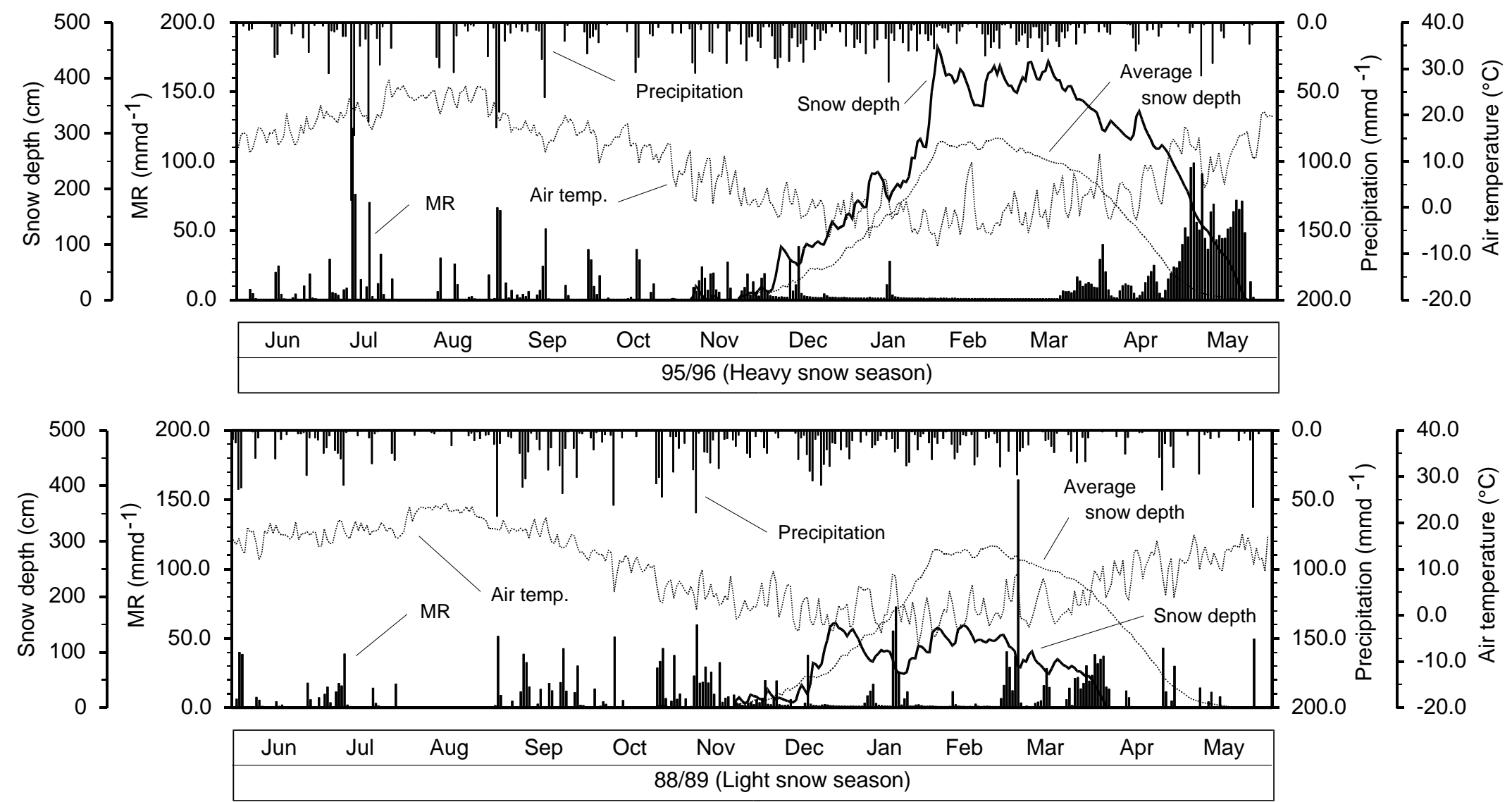

*Average snow depth : Average for eleven water years 


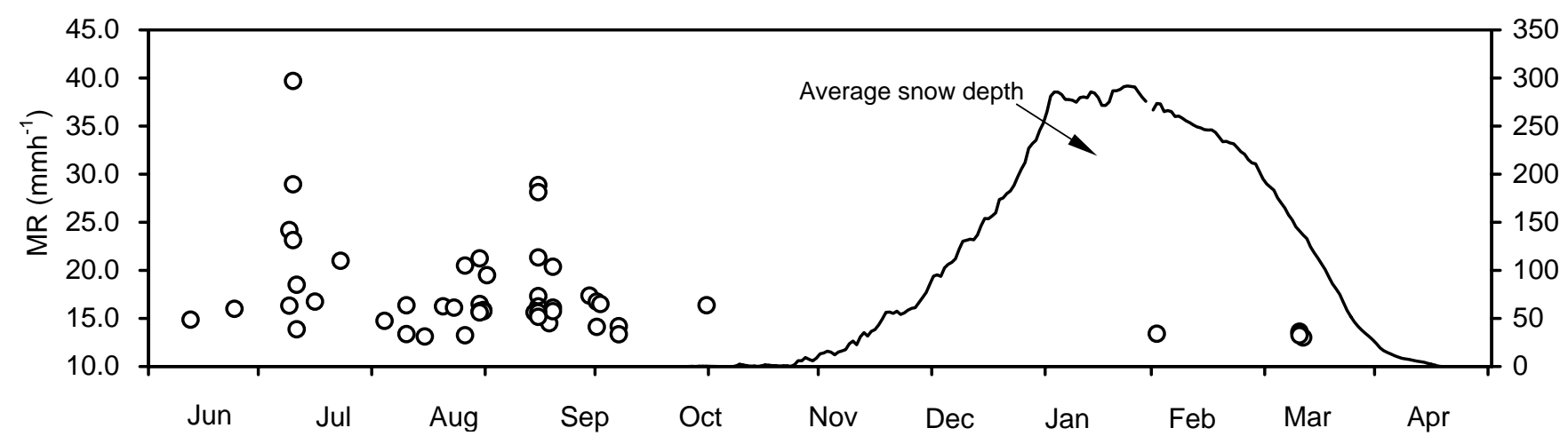

Figure 7 Hourly MR distribution of top-50 in the monitored eleven water years. 


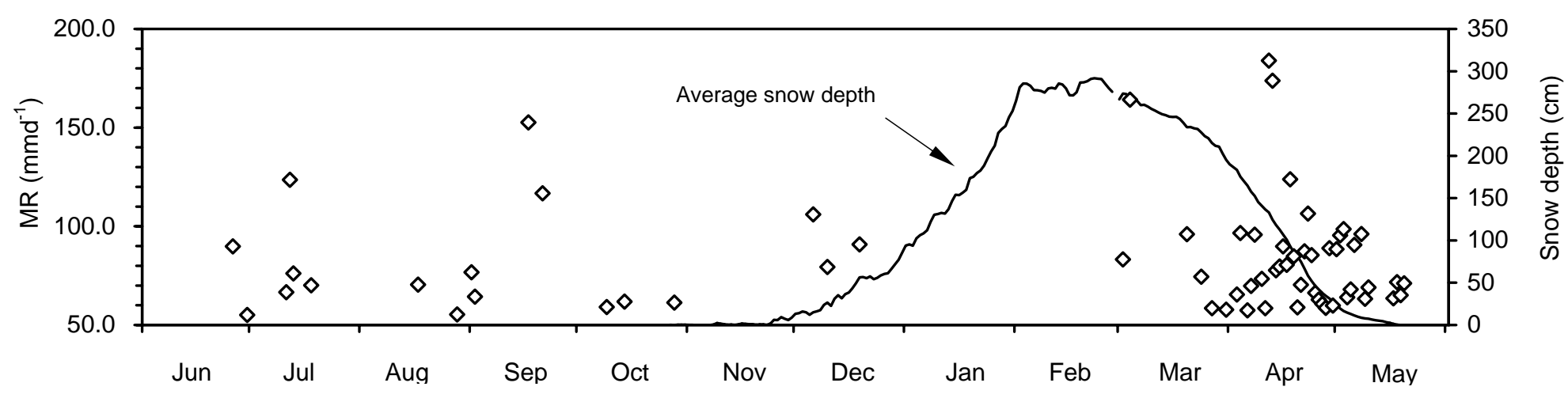

Figure 8 Daily MR distribution of top-50 in the monitored eleven water years. 


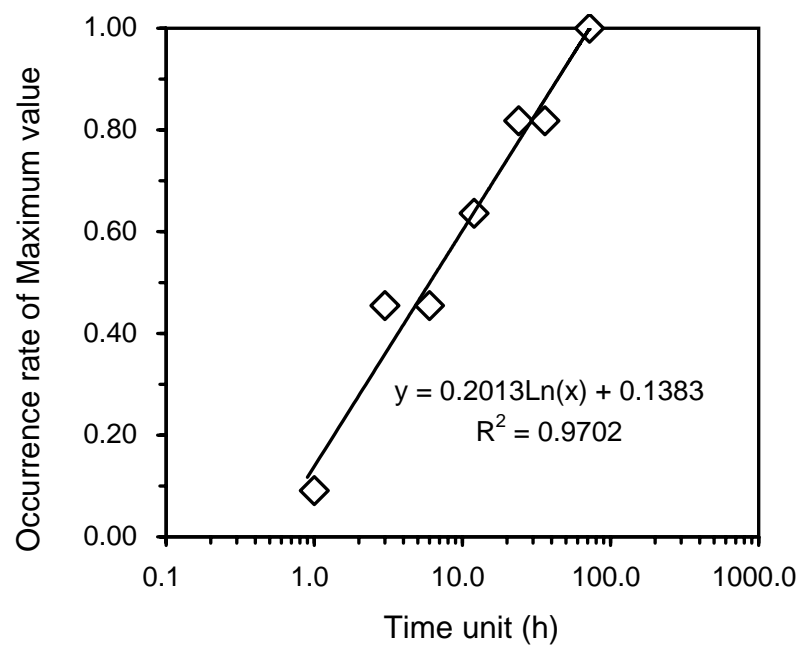

Figure 9 Relationship between time unit and occurrence rate of Maximum value in snow cover season. 


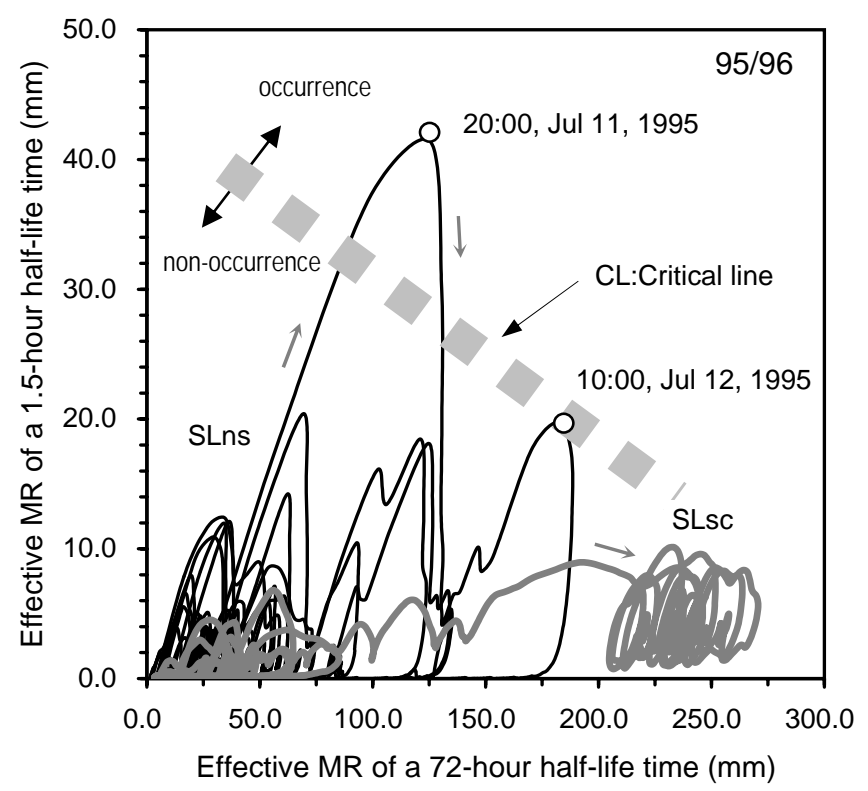

Figure 10 A comparison of a snake line of the non-snow cover season (SLns) and a snake line of the snow cover season (SLSc) of water year 95/96. 


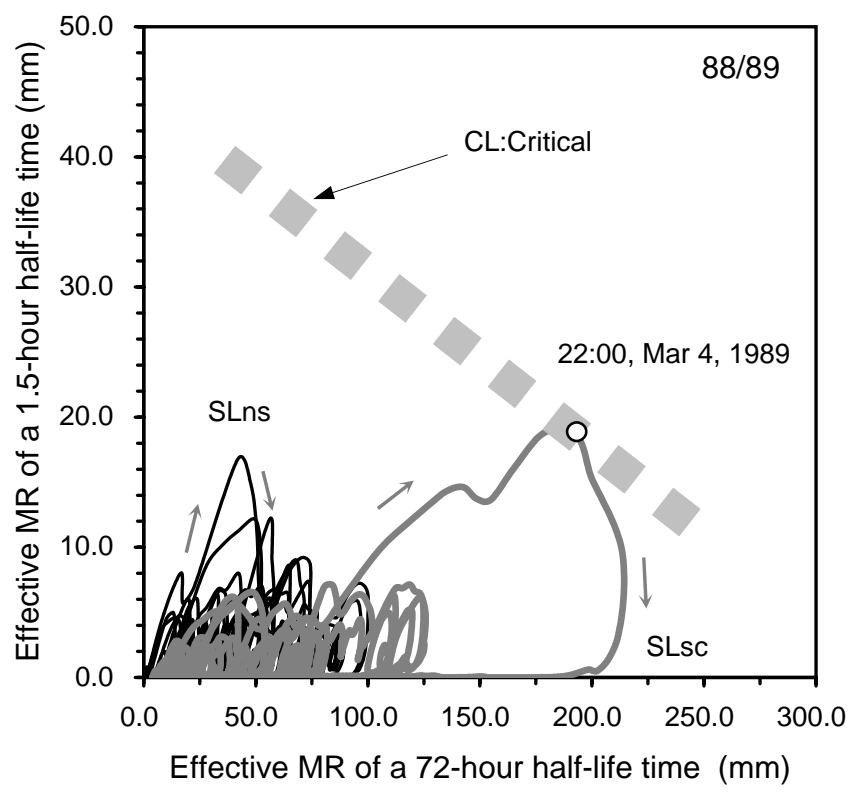

Figure 11 A comparison of a snake line of the non-snow cover season (SLns) and a snake line of the snow cover season (SLSc) of water year $88 / 89$. 


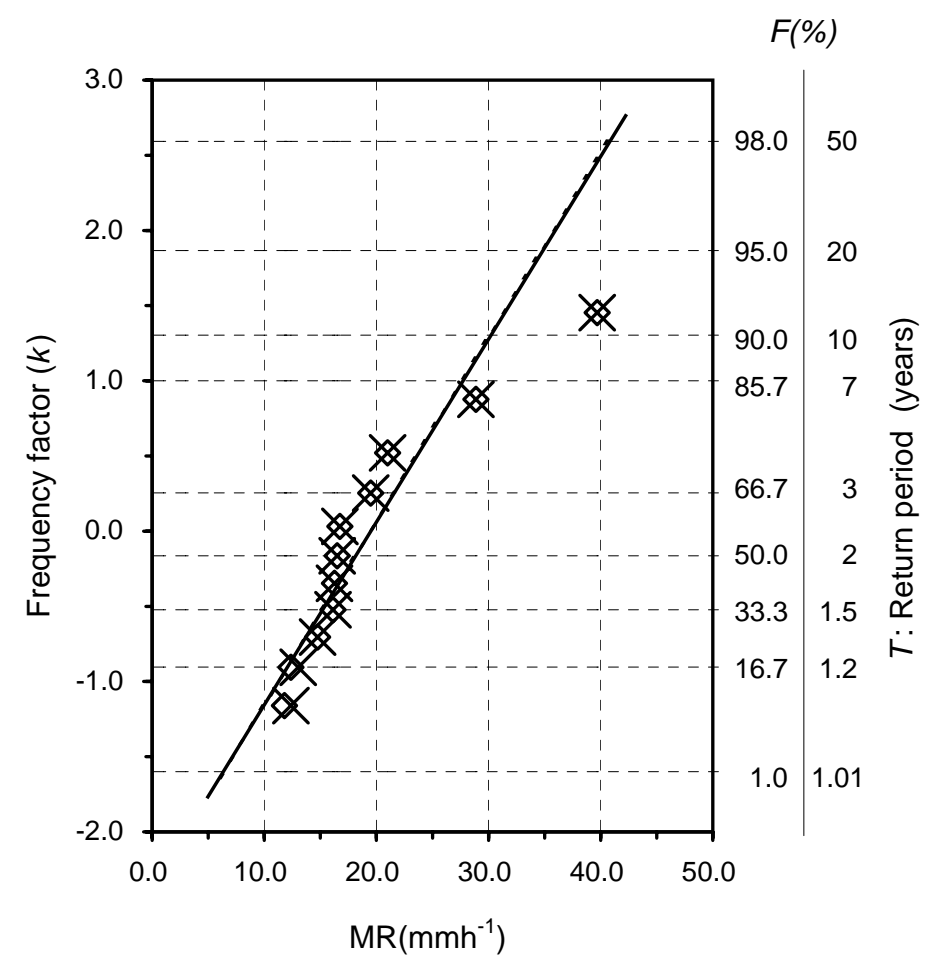

:Hourly value of MR for non- snow cover period (M $x$ : Hourly value of MR for snow cover period included (MR is)

Figure 12 Differences between the hourly values of MRns and MRis in extreme value distribution. 
$F(\%)$

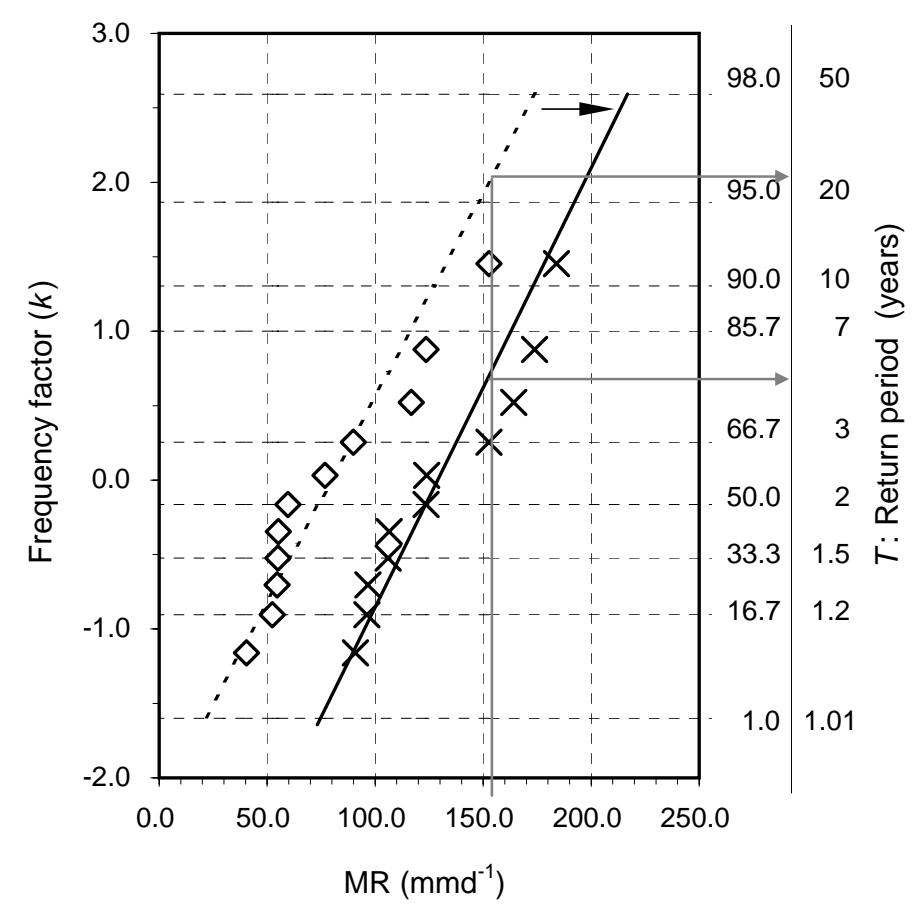

:Daily value of MR for non- snow cover period (MRns)

$\times$ : Daily value of MR for snow cover period included (MRis)

Figure 13 Differences between the daily values of MRns and MRis in extreme value distribution. 


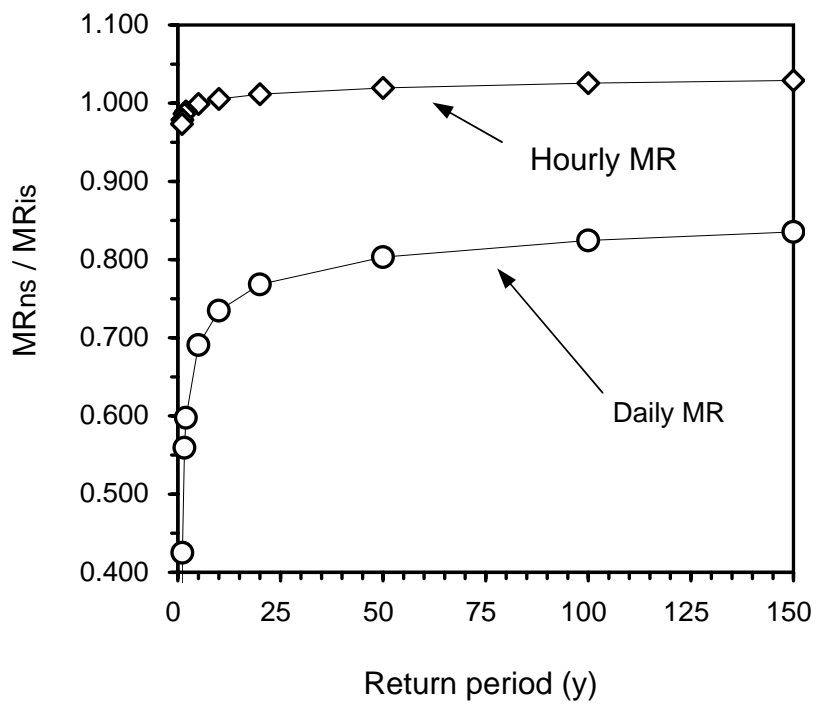

Figure 14 Relationship between return period and MRns/MRis. 
Table 1 Top-5 hourly MR distribution for each water year.

\begin{tabular}{|c|c|c|c|c|c|c|c|c|c|c|c|}
\hline Top & $88 / 89$ & $89 / 90$ & $90 / 91$ & 91/92 & $92 / 93$ & $93 / 94$ & $94 / 95$ & $95 / 96$ & $96 / 97$ & $97 / 98$ & 98/99 \\
\hline 1 & 19.5 & 16.4 & 21.0 & 16.5 & 16.3 & 14.9 & 16.8 & 39.7 & 16.1 & 13.0 & 28.9 \\
\hline 2 & 17.4 & 12.4 & 20.4 & 16.4 & 14.5 & 13.6 & 14.9 & 29.0 & 16.0 & 11.8 & 28.1 \\
\hline 3 & 13.4 & 11.0 & 16.1 & 15.8 & 9.9 & 13.5 & 13.0 & 23.1 & 11.9 & 11.8 & 24.2 \\
\hline 4 & 11.9 & 10.9 & 15.8 & 12.6 & 9.5 & 13.3 & 12.4 & 21.3 & 9.1 & 11.3 & 21.3 \\
\hline 5 & 11.6 & 10.5 & 15.6 & 11.3 & 8.9 & 13.3 & 10.1 & 18.5 & 8.9 & 11.2 & 20.5 \\
\hline
\end{tabular}

*Italic bold numerals were recorded in the snow cover period. 
Table 2 Top-5 daily MR distribution for each water year.

\begin{tabular}{|c|c|c|c|c|c|c|c|c|c|c|c|}
\hline Top & 88/89 & 89/90 & $90 / 91$ & $91 / 92$ & $92 / 93$ & 93/94 & $94 / 95$ & $95 / 96$ & $96 / 97$ & 97/98 & 98/99 \\
\hline 1 & 164.2 & 96.6 & 123.8 & 90.8 & 96.1 & 184.0 & 106.5 & 123.6 & 106.0 & 173.8 & 152.7 \\
\hline 2 & 72.6 & 95.8 & 116.8 & 83.2 & 85.4 & 76.2 & 88.9 & 98.6 & 89.9 & 96.0 & 75.9 \\
\hline 3 & 59.7 & 74.4 & 93.2 & 76.8 & 74.7 & 72.3 & 88.4 & 95.4 & 70.4 & 83.5 & 72.2 \\
\hline 4 & 55.3 & 73.4 & 89.9 & 72.2 & 68.0 & 69.1 & 87.3 & 90.6 & 69.8 & 58.5 & 70.5 \\
\hline 5 & 51.4 & 57.8 & 84.8 & 64.7 & 67.3 & 62.8 & 79.4 & 76.2 & 65.5 & 55.1 & 66.6 \\
\hline
\end{tabular}

*Italic bold numerals were recorded in the snow cover season. 
Table 3 Maximum values for each time unit for each water year.

\begin{tabular}{|c|c|c|c|c|c|c|c|c|c|c|c|}
\hline $\begin{array}{l}\text { Time unit } \\
\text { (hour) }\end{array}$ & 88/89 & $89 / 90$ & $90 / 91$ & $91 / 92$ & $92 / 93$ & $93 / 94$ & $94 / 95$ & $95 / 96$ & 96/97 & $97 / 98$ & $98 / 99$ \\
\hline 1 & 19.5 & 16.4 & 21.0 & 16.5 & 16.3 & 14.8 & 16.8 & 39.7 & 16.1 & 13.0 & 28.9 \\
\hline 3 & 37.0 & 33.0 & 44.4 & 41.3 & 24.6 & 39.3 & 31.9 & 91.8 & 32.4 & 36.2 & 78.4 \\
\hline 6 & 61.9 & 50.5 & 78.6 & 54.9 & 47.5 & 78.1 & 51.0 & 109.5 & 52.8 & 68.1 & 127.1 \\
\hline 12 & 112.1 & 71.4 & 106.5 & 75.1 & 71.6 & 149.5 & 68.8 & 119.6 & 78.3 & 109.2 & 152.7 \\
\hline 24 & 169.9 & 107.7 & 125.8 & 91.2 & 114.4 & 207.3 & 129.1 & 190.4 & 114.3 & 179.5 & 152.7 \\
\hline 36 & 203.2 & 159.1 & 214.5 & 127.1 & 177.8 & 253.2 & 203.1 & 199.8 & 139.5 & 276.5 & 156.7 \\
\hline 72 & 214.6 & 229.7 & 299.9 & 183.3 & 230.9 & 296.8 & 259.7 & 249.9 & 194.1 & 329.1 & 204.3 \\
\hline
\end{tabular}

